\title{
Induction of Heat Shock Protein-72 by Magnetic Nanofluid Hyperthermia in Cultured Retinal Ganglion Cells for Neuroprotective Treatment in Glaucoma
}

\author{
Jin Wook Jeoung, ${ }^{1}$ Minhong Jeun, ${ }^{2}$ Joo Hyun Park, ${ }^{1}$ Yu Jeong Kim, \\ Seongtae Bae, ${ }^{2,3}$ and Ki Ho Park ${ }^{1}$ \\ ${ }^{1}$ Department of Ophthalmology, Seoul National University Hospital, Seoul National University College of Medicine, \\ 101 Daehak-ro, Jongno-gu, Seoul 110-744, Republic of Korea \\ ${ }^{2}$ Biomagnetics Laboratory (BML), Department of Electrical and Computer Engineering, \\ National University of Singapore, Singapore 117576 \\ ${ }^{3}$ Department of Neurosurgery, Ischemic/Hypoxic Disease Institute, Biomedical Research Institute, and Cancer Research Institute, \\ Seoul National University College of Medicine, 101 Daehak-ro, Jongno-gu, Seoul 110-744, Republic of Korea \\ Correspondence should be addressed to Seongtae Bae; elebst@gmail.com and Ki Ho Park; kihopark@snu.ac.kr
}

Received 2 December 2014; Accepted 1 March 2015

Academic Editor: Zafar Iqbal

Copyright (C) 2015 Jin Wook Jeoung et al. This is an open access article distributed under the Creative Commons Attribution License, which permits unrestricted use, distribution, and reproduction in any medium, provided the original work is properly cited.

Background. Magnetic hyperthermia using superparamagnetic nanoparticle (SPNP) agents is considered a promising biotechnological approach to induce heat shock proteins (HSPs) in a target tissue because it can generate accurately controllable localized heating. Objectives. The main objective of this study is to demonstrate induction of HSPs in cultured retinal ganglion cells (RGCs) by using engineered $\mathrm{Mn}_{0.5} \mathrm{Zn}_{0.5} \mathrm{Fe}_{2} \mathrm{O}_{4}$ SPNP agents coated with polyethylene glycol (PEG) 500. Methods. The $\mathrm{Mn}_{0.5} \mathrm{Zn}_{0.5} \mathrm{Fe}_{2} \mathrm{O}_{4}$ nanoparticles were synthesized using a high temperature thermal decomposition method. The AC heating characteristics of PEG 500-coated $\mathrm{Mn}_{0.5} \mathrm{Zn}_{0.5} \mathrm{Fe}_{2} \mathrm{O}_{4}$ nanoparticles were investigated using an AC solenoid coil-capacitor system. Results. PEG 500coated SPNPs efficiently penetrated into the cytoplasm of RGCs without causing obvious cytological changes and showed stable and well-saturated self-heating temperature rise characteristics. Immunofluorescent staining images showed that AC magnetic hyperthermia successfully induced HSP72 in RGCs incubated with $\mathrm{Mn}_{0.5} \mathrm{Zn}_{0.5} \mathrm{Fe}_{2} \mathrm{O}_{4}$ nanoparticles. In Western blot analysis, a significant increase in immunoreactivity was observed for RGCs incubated with SPNPs in a fixed AC magnetic field $\left(f_{\text {appl }}=140 \mathrm{kHz}\right.$ and $H_{\text {appl }}=140 \mathrm{Oe}$ ). Conclusion. Our results demonstrate that the induction of HSP72 with a magnetic nanofluid hyperthermia could potentially be used as a neuroprotective treatment modality by way of enhancing a natural cytoprotective response.

\section{Introduction}

Glaucoma is characterized by progressive optic nerve damage with selective loss of retinal ganglion cells (RGCs) [1-3]. Recent clinical trials confirmed that the major modifiable risk factor for the development and progression of glaucoma is the intraocular pressure (IOP). The current treatment of glaucoma mainly involves reducing IOP and diurnal fluctuation. However, signs of glaucomatous progression can be seen in many patients with well-controlled IOP. In addition, disease onset and progression can occur in patients whose untreated
IOPs are within the normal range. From this background, the importance of neuroprotection in the treatment of glaucoma has become a worldwide issue. During the past decades, many studies have focused on discovering neuroprotective agents along with IOP lowering medications in order to prevent retinal ganglion cell (RGC) death or even reverse the process of cell death [4].

Heat shock proteins (HSPs), also known as stress proteins, are a group of proteins found in all living cells. It is rapidly induced by a variety of environmental stresses, such as hyperthermia, hypoxia, or ischemia, and its role is to protect 
cells against stress $[5,6]$. This protection mainly attributes to members of the HSP70 family, especially $72 \mathrm{kDa}$ heat shock protein (HSP72). HSP72, the major inducible form of the HSP70 family, has been found protecting cells from certain apoptotic stimuli such as oxidative stress, hypoxia, and inflammation [7-9].

Magnetic hyperthermia using superparamagnetic nanoparticle (SPNP) agents is considered a promising biotechnological approach to induce HSPs in a target tissue because it can generate accurately controllable localized heating [10, 11]. Recently, our group reported on the feasibility of achieving neuroprotection with magnetically engineered superparamagnetic $\mathrm{Mn}_{0.5} \mathrm{Zn}_{0.5} \mathrm{Fe}_{2} \mathrm{O}_{4}$ nanoparticles for localized HSP induction [12]. However, no empirical study on HSP expression in neuronal cells induced by magnetically engineered SPNP agents has been presented. The purpose of this study is to demonstrate induction of HSPs in cultured RGCs by local magnetic hyperthermia using engineered superparamagnetic $\mathrm{Mn}_{0.5} \mathrm{Zn}_{0.5} \mathrm{Fe}_{2} \mathrm{O}_{4}$ nanoparticle agents.

\section{Materials and Methods}

2.1. Materials. Fe (III) acetylacetonate (precursor, $>99.9 \%$ ), Mn (III) acetate tetrahydrate (99.99\%), Zn acetate dehydrate (99.999\%), oleic acid (surfactant, 90\%), oleylamine (surfactant, 70\%), 1,2-hexadecanediol (reductant, 90\%), and benzyl ether (solvent, 99\%) were purchased from Sigma-Aldrich to synthesize $\mathrm{Mn}_{0.5} \mathrm{Zn}_{0.5} \mathrm{Fe}_{2} \mathrm{O}_{4}$ SPNPs. In order to coat the SPNPs with polyethylene glycol (PEG, $500 \mathrm{Da})$, PEG and triethylamine were purchased from Gelest Inc. and SigmaAldrich, respectively.

\subsection{Synthesis of $\mathrm{Mn}_{0.5} \mathrm{Zn}_{0.5} \mathrm{Fe}_{2} \mathrm{O}_{4}$ and Coating with PEG 500}

2.2.1. Synthesis of $\mathrm{Mn}_{0.5} \mathrm{Zn}_{0.5} \mathrm{Fe}_{2} \mathrm{O}_{4} \cdot \mathrm{Mn}_{0.5} \mathrm{Zn}_{0.5} \mathrm{Fe}_{2} \mathrm{O}_{4}$ was synthesized using a high temperature thermal decomposition method. Mn (0.5 mmol), Zn (0.5 mmol), Fe (III) $(2 \mathrm{mmol})$, oleic acid ( $6 \mathrm{mmol})$, oleylamine $(6 \mathrm{mmol}), 1.2$ hexadecanediol $(10 \mathrm{mmol})$, and benzyl ether $(20 \mathrm{~mL})$ were mixed and gently stirred at room temperature. The ramping rate and heat treatment time were $13.3^{\circ} \mathrm{C} / \mathrm{min}$ and $45 \mathrm{~min}$, respectively. After heat treatment, the mixed solution was cooled to room temperature. Ethanol $(40 \mathrm{~mL})$ was added to the mixed solution to rinse the synthesized SPNPs, which were collected by centrifugation and then dried at room temperature.

2.2.2. Coating of $\mathrm{Mn}_{0.5} \mathrm{Zn}_{0.5} \mathrm{Fe}_{2} \mathrm{O}_{4}$ with PEG 500. The synthesized $\mathrm{Mn}_{0.5} \mathrm{Zn}_{0.5} \mathrm{Fe}_{2} \mathrm{O}_{4}$ SPNAs were coated with PEG $500 \mathrm{Da}$ to form a nanofluid. The SPNPs were dispersed in toluene (solvent, $7.5 \mathrm{~mL})$, and then PEG $(0.75 \mathrm{~mL})$ and triethylamine (catalyst, $3.75 \mathrm{~mL}$ ) were added. The mixed suspension was shaken for 24 hours at room temperature. The PEG 500-coated $\mathrm{Mn}_{0.5} \mathrm{Zn}_{0.5} \mathrm{Fe}_{2} \mathrm{O}_{4}$ SPNPs were then collected by centrifugation and dispersed in distilled water.

2.3. Cell Culture. Transformed RGC-5 retinal ganglion cells were cultured in Dulbecco's Modified Eagle Medium (DMEM, Invitrogen, Carlsbad, CA) containing 10\% fetal bovine serum
(FBS, Invitrogen), $100 \mathrm{U} / \mathrm{mL}$ penicillin/streptomycin (Invitrogen), and $2 \mathrm{mM}$ glutamine (Invitrogen) in a humidified incubator with $5 \% \mathrm{CO}_{2}$ at $37^{\circ} \mathrm{C}$.

2.4. In Vitro Cytotoxicity Assay: Analysis by Transmission Electron Microscopy (TEM). TEM analysis was conducted for the RGC- 5 cells treated with $\mathrm{Mn}_{0.5} \mathrm{Zn}_{0.5} \mathrm{Fe}_{2} \mathrm{O}_{4}$ particles to investigate the degree of SPNP penetration into the cells, cell apoptosis, and cell deformation, including nuclear fragmentation. RGC-5 cells were differentiated with $1 \mu \mathrm{M}$ staurosporine for 1 hour and incubated with $300 \mu \mathrm{g} / \mathrm{mL}$ SPNP for 24 hours. Cells were fixed with $2.5 \%$ glutaraldehyde and washed with PBS followed by $0.1 \mathrm{M}$ cacodylate buffer ( $\mathrm{pH}$ 7.2) and postfixed with $2 \%$ osmium tetroxide in $0.1 \mathrm{M}$ cacodylate buffer for 1.5 hours at room temperature. The samples were then washed briefly with distilled water, dehydrated in ethanol, infiltrated with propylene oxide (Acros Organics) and EPON mixed with epoxy resin (Embed 812, nadic methyl anhydride, Poly Med@ 812, dodecenyl succinic anhydride, dimethylaminomethyl phenol, Electron Microscopy Polysciences), and finally embedded with epoxy resin alone. The epoxy resin mixed samples were loaded into capsules and polymerized at $38^{\circ} \mathrm{C}$ for 12 hours and $60^{\circ} \mathrm{C}$ for 48 hours. Thin sections were made using an RMC MT-XL ultramicrotome, collected on a copper grid, and viewed with a JEOL (KEM$1400)$ at $80 \mathrm{kV}$ in the TEM mode.

2.5. Physical and Chemical Characterization of $\mathrm{Mn}_{0.5} \mathrm{Zn}_{0.5} \mathrm{Fe}_{2} \mathrm{O}_{4}$ SPNP Hyperthermia Agents. The shape, size, coating thickness, and size distribution of SPNPs were analyzed by highresolution transmission electron microscopy (HR-TEM). The $T_{\text {AC,mag }}$ of PEG 500-coated $\mathrm{Mn}_{0.5} \mathrm{Zn}_{0.5} \mathrm{Fe}_{2} \mathrm{O}_{4}$ SPNPs was characterized using an $\mathrm{AC}$ solenoid coil-capacitor system that we developed. The AC magnetically induced heating temperature of RGCs treated with the SPNPs $(500 \mu \mathrm{g} / \mathrm{mL})$ was measured at a fixed AC magnetic field of $f=140 \mathrm{kHz}$ and $H=140$ Oe. Heating stress was applied for times ranging from 600 to $1200 \mathrm{~s}$. In addition, measurements were taken of the heating characteristics of RGCs treated with SPNPs at concentrations from 300 to $700 \mu \mathrm{g} / \mathrm{mL}$ under the same AC magnetic heating conditions.

2.6. Induction of Heat Shock Protein by the Magnetic Nanofluid Hyperthermia System. The induction of HSPs by AC magnetic nanofluid hyperthermia was conducted using the high performance PEG 500-coated $\mathrm{Mn}_{0.5} \mathrm{Zn}_{0.5} \mathrm{Fe}_{2} \mathrm{O}_{4}$ SPNPs that we developed. In order to investigate the AC magnetically induced heating characteristics in RGCs, we developed an AC magnetic field generation system, which consists of AC coils, capacitors, DC power supplies, and wave generators (see Figure 1). This system was designed for both in vitro and in vivo pilot studies. The applied frequency of this system can be automatically controlled from 30 to $370 \mathrm{kHz}$, and the applied AC magnetic field can be simultaneously changed from 0 to $200 \mathrm{Oe}$ at each applied frequency.

Before magnetic hyperthermia, the RGC-5 cells were differentiated with $1 \mu \mathrm{M}$ staurosporine for 1 hour and incubated with $\mathrm{Mn}_{0.5} \mathrm{Zn}_{0.5} \mathrm{Fe}_{2} \mathrm{O}_{4}$ SPNPs for 24 hours. The cells were then washed with PBS (phosphate buffered saline) 


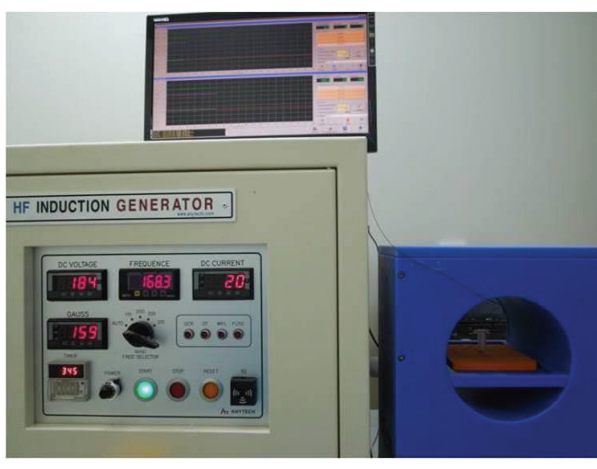

(a)

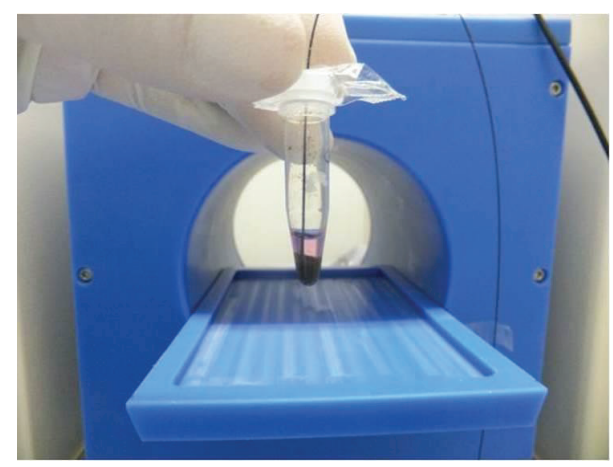

(b)

Figure 1: (a) An AC magnetic field generation system designed for both in vitro and in vivo hyperthermia studies. This system consists of AC coils, capacitors, DC power supplies, and wave generators. (b) Microcentrifuge tube containing RGCs with inserted optical thermometer.

and treated with trypsin-EDTA (Life Technologies, USA) followed by addition of an equal volume of culture medium. Cells were centrifuged for $5 \mathrm{~min}$; the supernatant was discarded and resuspended in culture medium. After a second 5 -minute centrifugation, the supernatant was again discarded and the cells were harvested into $0.1 \mathrm{~mL}$ of the medium in a $0.6 \mathrm{~mL}$ Eppendorf (E) tube.

After maintaining the temperature of the cells in the Etube at $37^{\circ} \mathrm{C}$ in a temperature-controlled bath, we placed the E-tube and cells in the center of the magnetic coil of an induction generator, monitoring the temperature while the generator operated. At the fixed applied frequency of $140 \mathrm{kHz}$, we controlled the temperature by increasing or decreasing the strength of the AC magnetic field. We maintained the target temperature of $41.0^{\circ} \mathrm{C}$ for the desired period before stopping the generator.

The RGCs incubated with $\mathrm{Mn}_{0.5} \mathrm{Zn}_{0.5} \mathrm{Fe}_{2} \mathrm{O}_{4}$ SPNPs were centrifuged to form a cell pellet. The tube and pelleted RGCs were immersed in a water bath to keep the temperature in the $36-37^{\circ} \mathrm{C}$ range. As shown in Figure 1, the temperature of the RGC-5 cells during hyperthermia was measured using an optical thermosensor (Fluoroptic temperature probe, Lumasense technologies, USA). The microcentrifuge tube with an optical thermometer inserted in the RGCs was placed at the center of the coil supplying the AC magnetic field. The warming rate of the SPNPs in the RGCs was controlled by changing the strength of $H_{\text {appl }}$ within the biologically and physiologically safe range of $120 \mathrm{Oe}\left(H_{\text {appl }} \cdot f_{\text {appl }}=1.34 \times\right.$ $\left.10^{9} \mathrm{~A} \mathrm{~m}^{-1} \mathrm{~s}^{-1}\right)-160$ Oe $\left(H_{\text {appl }} \cdot f_{\text {appl }}=1.78 \times 10^{9} \mathrm{~A} \mathrm{~m}^{-1} \mathrm{~s}^{-1}\right)$ at the fixed frequency of $140 \mathrm{kHz}$. The $T_{\mathrm{AC} \text {,mag }}$ of RGCs with SPNPs during HSPs induction was kept at $40.5^{\circ} \mathrm{C} \pm 0.5^{\circ} \mathrm{C}$ for $900 \mathrm{sec}$.

After 24 hours, the RGCs were counted and seeded onto a culture plate followed by fixation with $10 \%$ formaldehyde. The RGCs were washed twice with PBST (phosphate buffered saline tween-20) and then blocked. Anti-HSP72 (Enzo Life Sciences, USA) was added as primary antibody, followed by two washes with PBST. Alexa Fluor 488 goat anti-mouse IgG (FITC, fluorescein isothiocyanate) (Life Technologies, USA) was then added as secondary antibody, followed by two washes with PBST. To stain the nuclei, DAPI $\left(4^{\prime}, 6\right.$-diamino2-phenylindole) (Sigma, USA) was added, followed by two washes with PBST.

2.7. Western Blot Analysis. To quantify the induction of HSPs by hyperthermia using SPNPs, we performed Western blot analyses for four samples: three types of control group and an experimental sample with SPNPs $(500 \mu \mathrm{g} / \mathrm{mL})$ and a magnetic field $\left(f_{\text {appl }}=140 \mathrm{kHz}\right.$ and $\left.H_{\text {appl }}=140 \mathrm{Oe}\right)$ applied for $900 \mathrm{sec}$. For the analysis, harvested cells were lysed in a lysis buffer (Intron Biotechnology, Korea), loaded onto a 10\% SDS-polyacrylamide gel, and transferred to a polyvinylidene fluoride membrane. The membrane was blocked with dried nonfat milk and incubated with the primary antibody: Hsp72 antibody $(1: 1000$, Enzo Life Sciences, USA) and $\beta$-actin antibody $(1: 1000$, Sigma, USA). The membrane was washed with Tris-buffered saline containing $0.1 \%$ tween-20 and incubated with goat anti-mouse IgG $(1: 5000$, Santa Cruz, USA). The membrane was then washed and immunoblotting bands were detected using the WEST-ZOL detection system (iNtRON Biotechnology, Korea).

\section{Results and Discussion}

This study was designed to demonstrate induction of HSPs in cultured RGCs by using engineered superparamagnetic $\mathrm{Mn}_{0.5} \mathrm{Zn}_{0.5} \mathrm{Fe}_{2} \mathrm{O}_{4}$ nanoparticle agents. We employed a localized magnetic hyperthermia system by using the SPNP agents as a new nanobiotechnological approach to effectively control the local induction of HSP72. Magnetic hyperthermia using SPNP agents is considered a promising biotechnological approach to the induction of HSPs in target tissues because it can generate localized heating with accurate temperature control. Evidence suggests that manipulation of the cellular stress response may be a strategy to protect neurons from damage following cerebral ischemia [13-15] or during the progression of neurodegenerative conditions such as Alzheimer's disease [16, 17], Parkinson's disease [18], and glaucoma [19-21]. In this study, we demonstrate that the induction of HSPs by localized magnetic hyperthermia using 


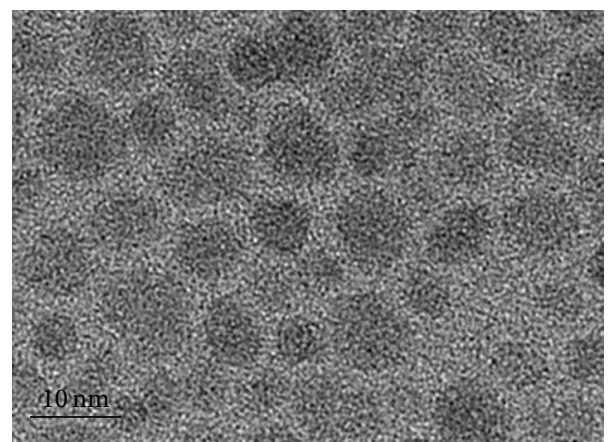

FIGURE 2: High-resolution transmission electron microscopy image of superparamagnetic PEG 500-coated $\mathrm{Mn}_{0.5} \mathrm{Zn}_{0.5} \mathrm{Fe}_{2} \mathrm{O}_{4}$ nanoparticles dispersed in distilled water.

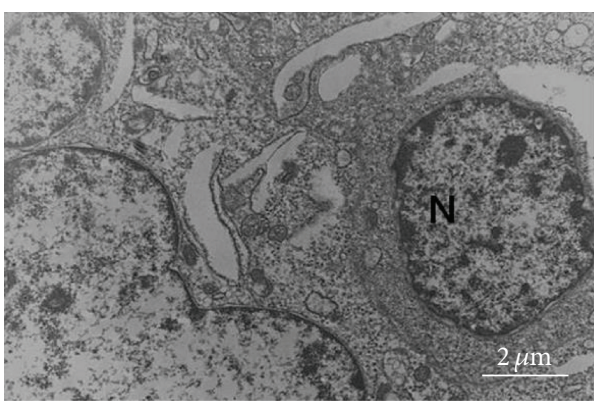

(a)

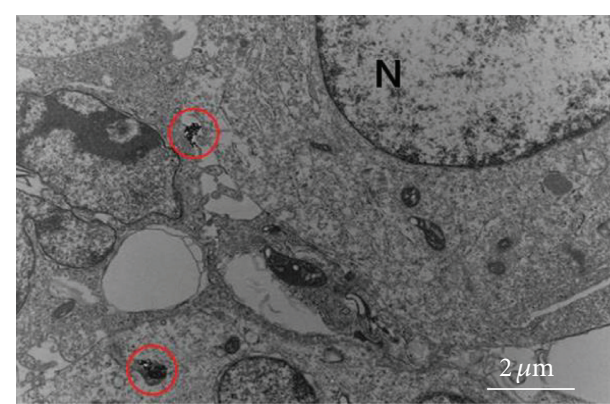

(b)

FIGURE 3: Transmission electron microscopy image of RGCs treated with PEG 500-coated $\mathrm{Mn}_{0.5} \mathrm{Zn}_{0.5} \mathrm{Fe}_{2} \mathrm{O}_{4}$ nanoparticles. Nanoparticles (red circles) were found in the cytoplasm, but not in the nucleus $(\mathrm{N})$, and they caused no morphological deformation. (a) Control, (b) $30 \mu \mathrm{g} / \mathrm{mL}$ $\mathrm{Mn}_{0.5} \mathrm{Zn}_{0.5} \mathrm{Fe}_{2} \mathrm{O}_{4}$.

engineered SPNPs is promisingly feasible for neuroprotection modality.

3.1. Characterization of PEG 500-Coated $\mathrm{Mn}_{0.5} \mathrm{Zn}_{0.5} \mathrm{Fe}_{2} \mathrm{O}_{4}$. Figure 2 shows the HR-TEM images of PEG 500-coated $\mathrm{Mn}_{0.5} \mathrm{Zn}_{0.5} \mathrm{Fe}_{2} \mathrm{O}_{4}$ nanoparticles. The PEG 500-coated $\mathrm{Mn}_{0.5} \mathrm{Zn}_{0.5} \mathrm{Fe}_{2} \mathrm{O}_{4}$ nanoparticles have a round shape with a mean size of $7.20 \pm 0.85 \mathrm{~nm}$ and a narrow size distribution, and they are well segregated.

3.2. In Vitro Biocompatibility of PEG 500-Coated $\mathrm{Mn}_{0.5} \mathrm{Zn}_{0.5} \mathrm{Fe}_{2} \mathrm{O}_{4}$ Particles. In vitro biocompatibility was evaluated using TEM to study the degree of particle penetration into RGCs and any cytological changes caused by this penetration. Figure 3 illustrates that the PEG 500-coated SPNPs efficiently penetrated into the cytoplasm of RGCs without causing obvious cytological changes such as cell deformation or apoptosis. In addition, we found that the SPNPs did not penetrate the nuclei of RGCs, and so did not cause nuclear fragmentation.

Our results suggest that these SPNPs can be located inside cells with no significant structural or morphological adverse effects. Furthermore, the PEG 500-coated nanoparticles inside the cells showed less agglomeration than those in our previous report [12], which may be due to the PEG coating and its weakly positively charged or uncharged surface. The results of TEM analyses of cultured RGCs suggest the potential feasibility of the coated nanoparticles as a localized hyperthermic agent for neuroprotection.

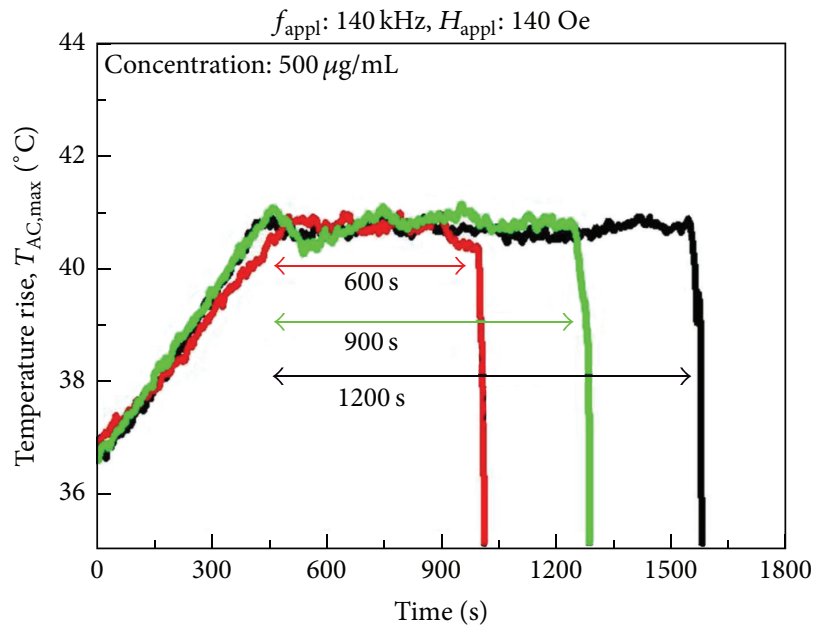

FIGURE 4: AC magnetically induced heating temperatures of RGCs treated with SPNPs $(500 \mu \mathrm{g} / \mathrm{mL})$ with different holding time of AC heating from $600 \mathrm{sec}$ to $1200 \mathrm{sec}$. Applied frequency and magnetic field strength were constant at $140 \mathrm{kHz}$ and $140 \mathrm{Oe}$, respectively. The temperature was controlled at a typical HSPs induction temperature of $41.0 \pm 0.5^{\circ} \mathrm{C}$.

3.3. Characteristics of AC Magnetically Induced Heating by $\mathrm{Mn}_{0.5} \mathrm{Zn}_{0.5} \mathrm{Fe}_{2} \mathrm{O}_{4}$ Nanoparticles. Figure 4 shows the temperatures of RGC treated with SPNPs $(500 \mu \mathrm{g} / \mathrm{mL})$ during AC 


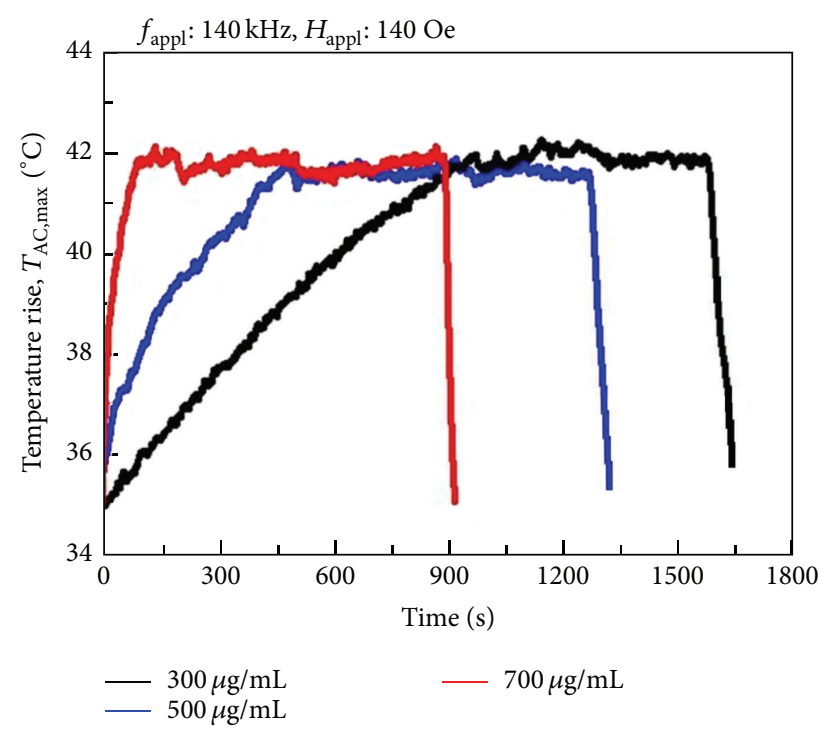

FIGURE 5: AC magnetically induced temperature rise characteristics of RGCs treated with PEG 500-coated $\mathrm{Mn}_{0.5} \mathrm{Zn}_{0.5} \mathrm{Fe}_{2} \mathrm{O}_{4}$ nanoparticles. Measurements were taken at the fixed applied frequency of $140 \mathrm{kHz}$ and magnetic field of $140 \mathrm{Oe}$, with nanoparticle concentrations ranging from $300 \mu \mathrm{g} / \mathrm{mL}$ to $700 \mu \mathrm{g} / \mathrm{mL}$. This figure describes the dependence of $T_{\mathrm{AC}, \max }$ characteristics on SPNP concentration.

magnetically induced heating. AC heating stress times varied from $600 \mathrm{sec}$ to $1200 \mathrm{sec}$. The applied frequency and magnetic field were fixed at $f=110 \mathrm{kHz}$ and $H=140 \mathrm{Oe}$, respectively, which are in the biologically safe and physiologically tolerable range. The PEG 500-coated nanoparticles produced stable and well-saturated heating characteristics. The temperature was controlled at a typical HSPs induction temperature of $41.0 \pm 0.5^{\circ} \mathrm{C}$.

Figure 5 shows the AC magnetically induced heating temperature rise characteristics of RGCs treated with PEG 500coated $\mathrm{Mn}_{0.5} \mathrm{Zn}_{0.5} \mathrm{Fe}_{2} \mathrm{O}_{4}$ nanoparticles. The applied magnetic field and $\mathrm{AC}$ frequency were fixed at $H_{\mathrm{appl}}=140$ Oe and $f_{\mathrm{appl}}=$ $140 \mathrm{kHz}$, respectively, and the concentration of the nanofluid varied from $300 \mu \mathrm{g} / \mathrm{mL}$ to $700 \mu \mathrm{g} / \mathrm{mL}$ to explore the effects on HSP72 induction efficiency. As can be seen in Figure 5, the $T_{\mathrm{AC} \text {, max }}$ characteristics and the corresponding AC heating response were strongly dependent on the concentration of the SPNPs (nanofluid solutions).

3.4. Induction of Heat Shock Protein by Magnetic Hyperthermia In Vitro. In this study, 3 types of control groups were used: (1) no SPNPs and no AC magnetic field, (2) no SPNPs but AC magnetic field applied $\left(f_{\text {appl }}=140 \mathrm{kHz}\right.$ and $H_{\text {appl }}=$ $140 \mathrm{Oe})$, and (3) RGCs incubated with SPNPs $(500 \mu \mathrm{g} / \mathrm{mL})$ but no applied AC magnetic field. Figure 6 shows immunofluorescent staining images of HSP72 in RGCs treated with $\mathrm{Mn}_{0.5} \mathrm{Zn}_{0.5} \mathrm{Fe}_{2} \mathrm{O}_{4}$ nanoparticles after magnetic hyperthermia for $900 \mathrm{~s}$ at $41.0 \pm 0.5^{\circ} \mathrm{C}$. In this study, the RGCs were stained using FITC and DAPI with antibodies to HSP72. As can be seen in Figure 6, HSP72 was not induced in the control groups 1, 2, and 3. However, HSP72 was successfully induced in RGCs incubated with $\mathrm{Mn}_{0.5} \mathrm{Zn}_{0.5} \mathrm{Fe}_{2} \mathrm{O}_{4}$ nanoparticles and an adequate $\mathrm{AC}$ magnetic field. In addition, we found that the induction efficiency of HSP72 and cell death rate have a strong dependence on the temperature ramp rate, which was controlled by the externally applied AC magnetic field: cells experiencing a slower temperature elevation rate had more HSP72 induction and minimal cell loss.

Specific biotechnical requirements [12] for any SPNP considered to be an agent for HSP induction are as follows: (1) it should have a high specific absorption rate, which enables it to rapidly reach the induction temperature (39$41^{\circ} \mathrm{C}$ ) while the concentration of SPNPs is kept as low as possible; (2) it must reach the induction temperature with an applied magnetic field and frequency that fall within the ranges to ensure avoidance of bioelectrically induced damage [10] (i.e., $H<190 \mathrm{Oe}$ and $f<120 \mathrm{kHz}$ ); and (3) it must be highly biocompatible and should easily penetrate the target cells. Our results demonstrate that PEG 500-coated $\mathrm{Mn}_{0.5} \mathrm{Zn}_{0.5} \mathrm{Fe}_{2} \mathrm{O}_{4}$ nanoparticles exhibited heating temperature characteristics that were stable and controllable at a typical HSP induction temperature of $41.0 \pm 0.5^{\circ} \mathrm{C}$. Additionally, in this study, the temperature ramp rate was controlled by changing $H_{\text {appl }}$ within the range from $120 \mathrm{Oe}$ to $160 \mathrm{Oe}$ at a fixed frequency of $140 \mathrm{kHz}$. The experimental results suggest that HSPs can be successfully induced in cultured RGCs while the applied magnetic field is maintained within a biologically and physiologically safe range.

3.5. Quantitative Analysis of HSP72 Expression by Western Blot Analysis. HSP72 expression in cultured RGCs was quantified by Western blot analysis (Figure 7). There were weak immunoreactivities for HSP72 in the control groups 1,2 , and 3. However, a strong increase of immunoreactivity was observed in RGCs incubated with $\mathrm{Mn}_{0.5} \mathrm{Zn}_{0.5} \mathrm{Fe}_{2} \mathrm{O}_{4}$ nanoparticles under the fixed $\mathrm{AC}$ magnetic field $\left(f_{\mathrm{appl}}=\right.$ $140 \mathrm{kHz}$ and $H_{\text {appl }}=140 \mathrm{Oe}$ ).

As can be seen in Figure 6, we confirmed that HSP72 was successfully induced in RGCs incubated with $\mathrm{Mn}_{0.5} \mathrm{Zn}_{0.5} \mathrm{Fe}_{2} \mathrm{O}_{4}$ nanoparticles when an appropriate 
Anti-HSP72
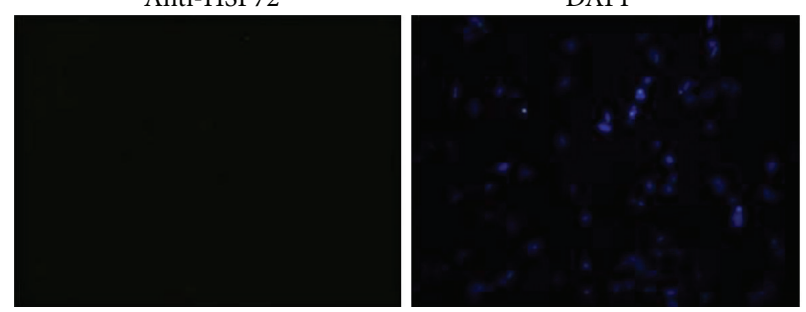

(a)
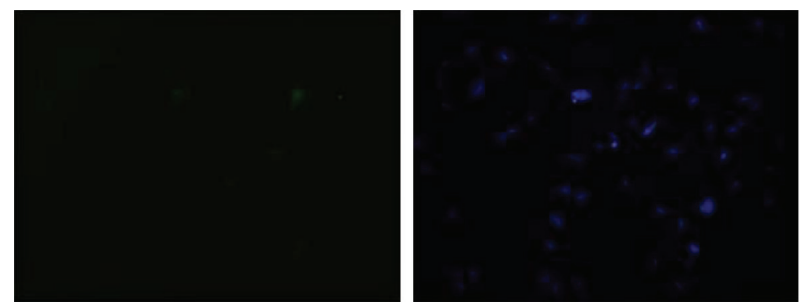

(b)
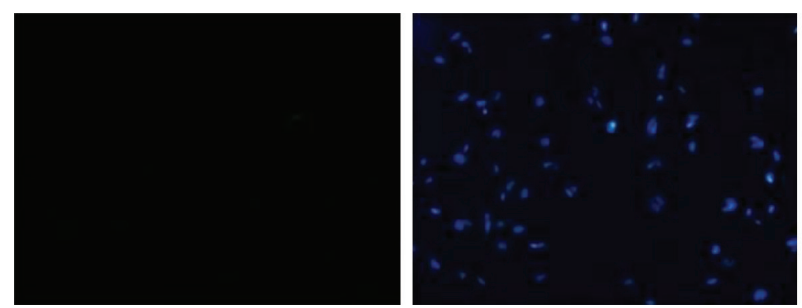

(c)
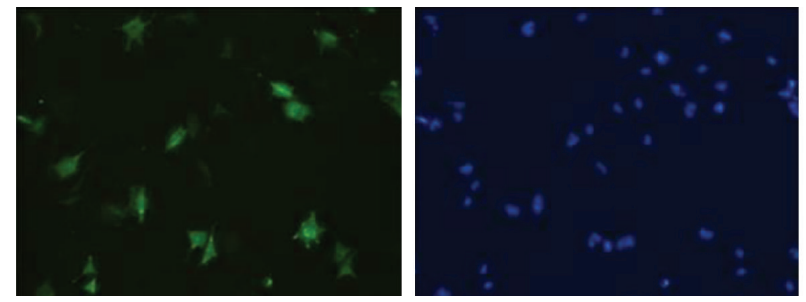

(d)
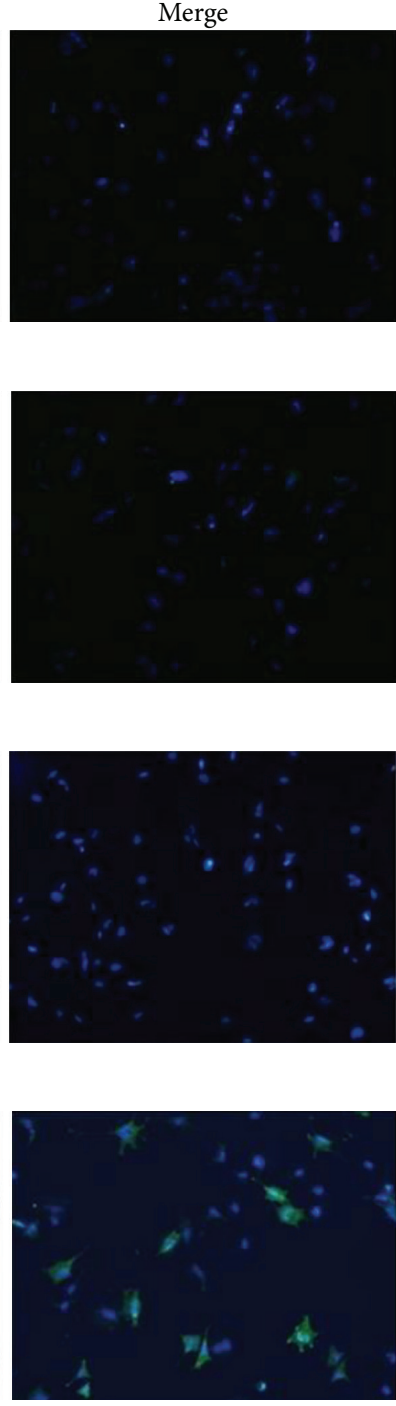

FIGURE 6: Immunofluorescent staining of HSP72. (a) Control group 1, without SPNPs and without magnetic field application. (b) Control group 2, without SPNPs but with magnetic field application ( $f_{\text {appl }}=140 \mathrm{kHz}$ and $\left.H_{\text {appl }}=140 \mathrm{Oe}\right)$. (c) Control group 3, without magnetic field application but incubated with SPNPs $(500 \mu \mathrm{g} / \mathrm{mL})$. (d) RGCs incubated with SPNPs $(500 \mu \mathrm{g} / \mathrm{mL})$ and with the AC magnetic field applied $\left(f_{\text {appl }}=140 \mathrm{kHz}\right.$ and $H_{\text {appl }}=140 \mathrm{Oe}$ ). HSP72 was not induced in the control groups 1, 2, and 3 but was successfully induced in RGCs incubated with SPNPs when an adequate magnetic field was applied.

magnetic field was applied. The results of Western blot analyses also showed a strong increase in the immunoreactivity of similarly treated RGCs. However, induction of HSP72 was not observed in the control group 3, indicating that mechanical stress due to incubation with $\mathrm{Mn}_{0.5} \mathrm{Zn}_{0.5} \mathrm{Fe}_{2} \mathrm{O}_{4}$ nanoparticles does not contribute to the induction of HSP72. In addition, the application of only the external magnetic field without SPNP agents (control group 2) does not induce HSP72 in cultured RGCs. Furthermore, it was found that the induction efficiency of HSP72 and the cell death rate are highly dependent on the temperature ramp rate. We speculate that a too rapid increase in temperature by using SPNP agents may inhibit RGCs from keeping enough thermal energy to induce stress proteins such as HSP72.
Moreover, the more rapid temperature rise might lead to higher RGC cell death during HSP induction.

Based on these results, the application of SPNP agents could be a promising biotechnical method for inducing localized HSP72. Because of specific limitations to intravenous injection of nanoparticles into the choroid, the SPNP agents can be injected into the intravitreal space of the eye. In a study performed by our group, the injected nanoparticles successfully diffused into the retina, with most found in the inner plexiform layer [12]. This is the layer most adjacent to the RGCs; therefore, highly effective heat transfer to the RGCs can be expected. These findings suggest that SPNP agents could potentially be used as neuroprotective mediators in glaucoma treatment. 


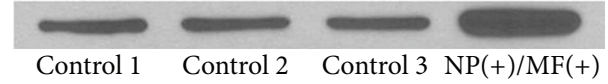

(a)

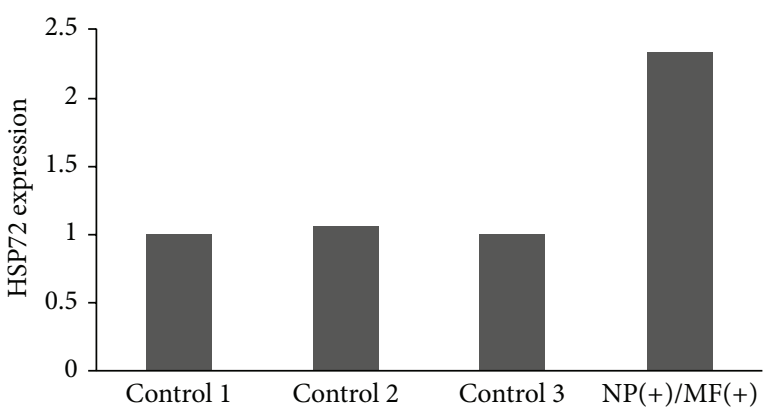

(b)

FIgURE 7: Western blot analysis of HSP72. (1) Control group 1, without SPNPs and without magnetic field application. (2) Control group 2, without SPNPs but with magnetic field application $\left(f_{\text {appl }}\right.$ $=140 \mathrm{kHz}$ and $H_{\text {appl }}=140 \mathrm{Oe}$ ). (3) Control group 3, without magnetic field application but incubated with SPNPs $(500 \mu \mathrm{g} / \mathrm{mL})$. (4) $\mathrm{NP}(+) / \mathrm{MF}(+)$ group, RGCs incubated with SPNPs $(500 \mu \mathrm{g} / \mathrm{mL})$ and with the application of AC magnetic field ( $f_{\text {appl }}=140 \mathrm{kHz}$ and $H_{\text {appl }}=140$ Oe).

\section{Conclusions}

We successfully induced HSP72 in cultured RGCs with hyperthermia via SPNPs, PEG 500-coated $\mathrm{Mn}_{0.5} \mathrm{Zn}_{0.5} \mathrm{Fe}_{2} \mathrm{O}_{4}$. Considering that glaucoma ultimately causes RGC death, an endogenous neuroprotection strategy through induction of an HSP response can widen the field of glaucoma treatment. Furthermore, our results suggest that the $\mathrm{Mn}_{0.5} \mathrm{Zn}_{0.5} \mathrm{Fe}_{2} \mathrm{O}_{4}$ nanoparticles could be used as a neuroprotective treatment method for cerebral ischemia and neurodegenerative diseases such as Alzheimer's disease and Parkinson's disease. Further studies with animal models and functional evaluations will be necessary to confirm $\mathrm{Mn}_{0.5} \mathrm{Zn}_{0.5} \mathrm{Fe}_{2} \mathrm{O}_{4}$ nanoparticles as potential novel neuroprotective therapeutic agents.

\section{Conflict of Interests}

The authors have no proprietary or financial interest in any products or techniques described in the article.

\section{Authors' Contribution}

Jin Wook Jeoung and Minhong Jeun equally contributed as co-first authors.

\section{Acknowledgment}

This work was supported by Grant no. 03-2010-0060 from the SNUH Research Fund Korea).

\section{References}

[1] H. A. Quigley, G. R. Dunkelberger, and W. R. Green, "Chronic human glaucoma causing selectively greater loss of large optic nerve fibers," Ophthalmology, vol. 95, no. 3, pp. 357-363, 1988.
[2] Y. Glovinsky, H. A. Quigley, and G. R. Dunkelberger, "Retinal ganglion cell loss is size dependent in experimental glaucoma," Investigative Ophthalmology \& Visual Science, vol. 32, no. 3, pp. 484-491, 1991.

[3] A. Sommer, J. Katz, H. A. Quigley et al., "Clinically detectable nerve fiber atrophy precedes the onset of glaucomatous field loss," Archives of Ophthalmology, vol. 109, no. 1, pp. 77-83, 1991.

[4] N. Nilforushan, "Neuroprotection in glaucoma," Journal of Ophthalmic and Vision Research, vol. 7, no. 1, pp. 91-93, 2012.

[5] V. L. Gabai, A. B. Meriin, J. A. Yaglom, V. Z. Volloch, and M. Y. Sherman, "Role of Hsp70 in regulation of stress-kinase JNK: implications in apoptosis and aging," FEBS Letters, vol. 438, no. 1-2, pp. 1-4, 1998.

[6] M. Jäättelä, "Heat shock proteins as cellular lifeguards," Annals of Medicine, vol. 31, no. 4, pp. 261-271, 1999.

[7] B. Fauconneau, V. Petegnief, C. Sanfeliu, A. Piriou, and A. M. Planas, "Induction of heat shock proteins (HSPs) by sodium arsenite in cultured astrocytes and reduction of hydrogen peroxide-induced cell death," Journal of Neurochemistry, vol. 83, no. 6, pp. 1338-1348, 2002.

[8] H.-S. Park, S.-G. Cho, C. K. Kim et al., "Heat shock protein Hsp72 is a negative regulator of apoptosis signal-regulating kinase 1," Molecular and Cellular Biology, vol. 22, no. 22, pp. 7721-7730, 2002.

[9] K. Suzuki, B. Murtuza, I. A. Sammut et al., "Heat shock protein 72 enhances manganese superoxide dismutase activity during myocardial ischemia-reperfusion injury, associated with mitochondrial protection and apoptosis reduction," Circulation, vol. 106, no. 12, supplement 1, pp. I270-I276, 2002.

[10] M. Johannsen, U. Gneveckow, L. Eckelt et al., "Clinical hyperthermia of prostate cancer using magnetic nanoparticles: presentation of a new interstitial technique," International Journal of Hyperthermia, vol. 21, no. 7, pp. 637-647, 2005.

[11] R. A. Frimpong and J. Z. Hilt, "Magnetic nanoparticles in biomedicine: synthesis, functionalization and applications," Nanomedicine, vol. 5, no. 9, pp. 1401-1414, 2010.

[12] M. Jeun, J. W. Jeoung, S. Moon et al., "Engineered superparamagnetic $\mathrm{Mn}_{0.5} \mathrm{Zn}_{0.5} \mathrm{Fe}_{2} \mathrm{O}_{4}$ nanoparticles as a heat shock protein induction agent for ocular neuroprotection in glaucoma," Biomaterials, vol. 32, no. 2, pp. 387-394, 2011.

[13] S. Rajdev, K. Hara, Y. Kokubo et al., "Mice overexpressing rat heat shock protein 70 are protected against cerebral infarction," Annals of Neurology, vol. 47, no. 6, pp. 782-791, 2000.

[14] B. Hoehn, T. M. Ringer, L. Xu et al., "Overexpression of HSP72 after induction of experimental stroke protects neurons from ischemic damage," Journal of Cerebral Blood Flow \& Metabolism, vol. 21, no. 11, pp. 1303-1309, 2001.

[15] R. G. Giffard, L. Xu, H. Zhao et al., "Chaperones, protein aggregation, and brain protection from hypoxic/ischemic injury," Journal of Experimental Biology, vol. 207, no. 18, pp. 3213-3220, 2004.

[16] J. Magrané, R. C. Smith, K. Walsh, and H. W. Querfurth, "Heat shock protein 70 participates in the neuroprotective response to intracellularly expressed beta-amyloid in neurons," The Journal of Neuroscience, vol. 24, no. 7, pp. 1700-1706, 2004.

[17] R. C. Smith, K. M. Rosen, R. Pola, and J. Magrané, "Stress proteins in Alzheimer's disease," International Journal of Hyperthermia, vol. 21, no. 5, pp. 421-431, 2005.

[18] P. K. Auluck, H. Y. E. Chan, J. Q. Trojanowski, V. M.-Y. Lee, and N. M. Bonini, "Chaperone suppression of $\alpha$-synuclein toxicity in a Drosophila model for Parkinson's disease," Science, vol. 295, no. 5556, pp. 865-868, 2002. 
[19] K. H. Park, F. Cozier, O. C. Ong, and J. Caprioli, "Induction of heat shock protein 72 protects retinal ganglion cells in a rat glaucoma model," Investigative Ophthalmology \& Visual Science, vol. 42, no. 7, pp. 1522-1530, 2001.

[20] Y. Ishii, J. M. K. Kwong, and J. Caprioli, "Retinal ganglion cell protection with geranylgeranylacetone, a heat shock protein inducer, in a rat glaucoma model," Investigative Ophthalmology and Visual Science, vol. 44, no. 5, pp. 1982-1992, 2003.

[21] S. J. Kim, Y. J. Kim, and K. H. Park, "Neuroprotective effect of transpupillary thermotherapy in the optic nerve crush model of the rat," Eye, vol. 23, no. 3, pp. 727-733, 2009. 

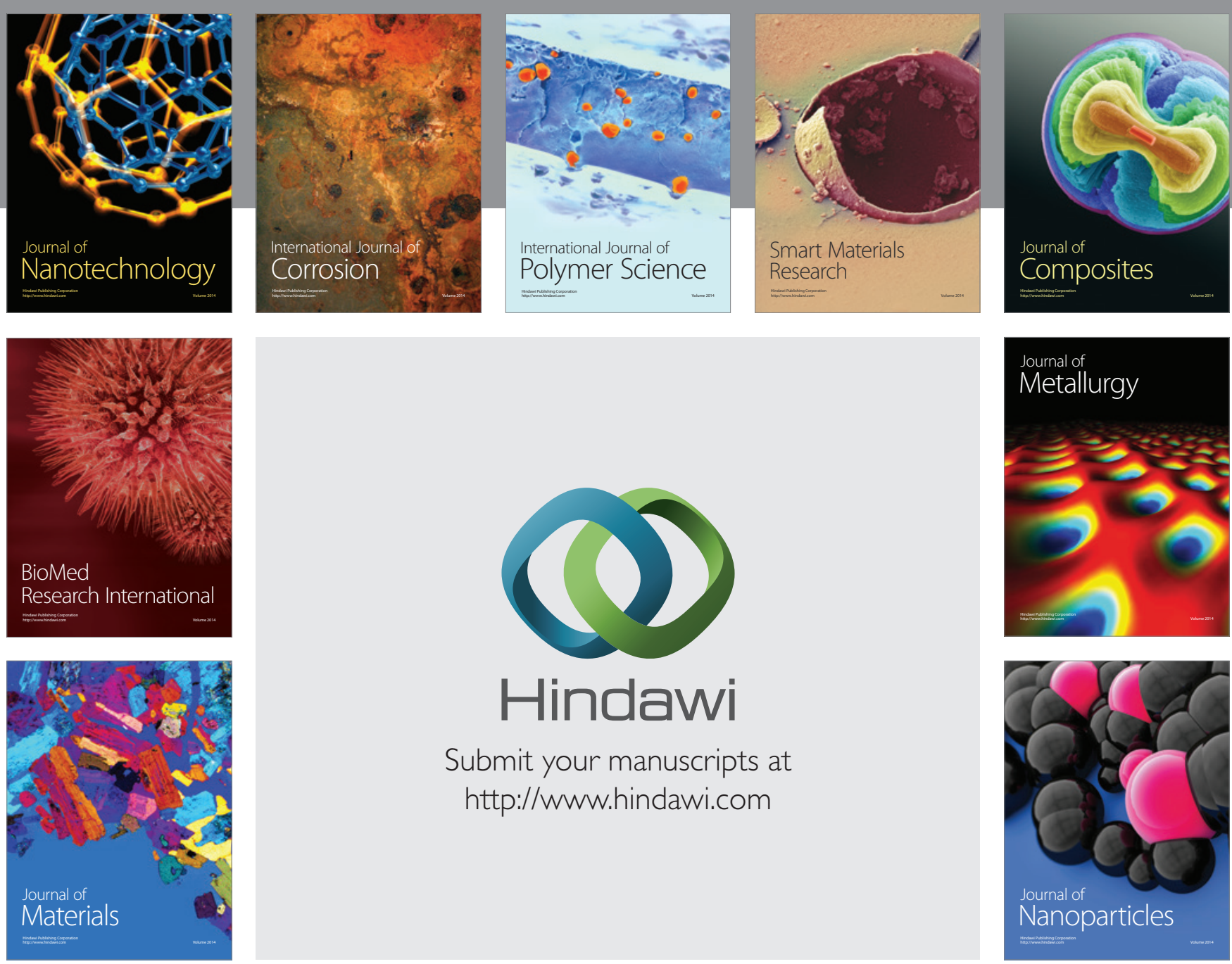

Submit your manuscripts at http://www.hindawi.com
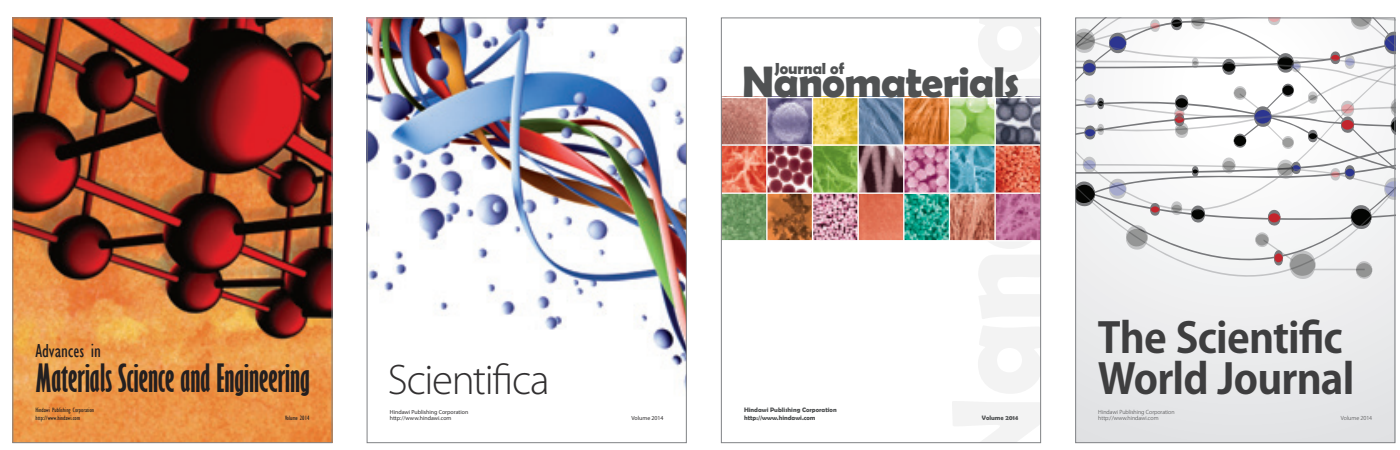

\section{The Scientific World Journal}
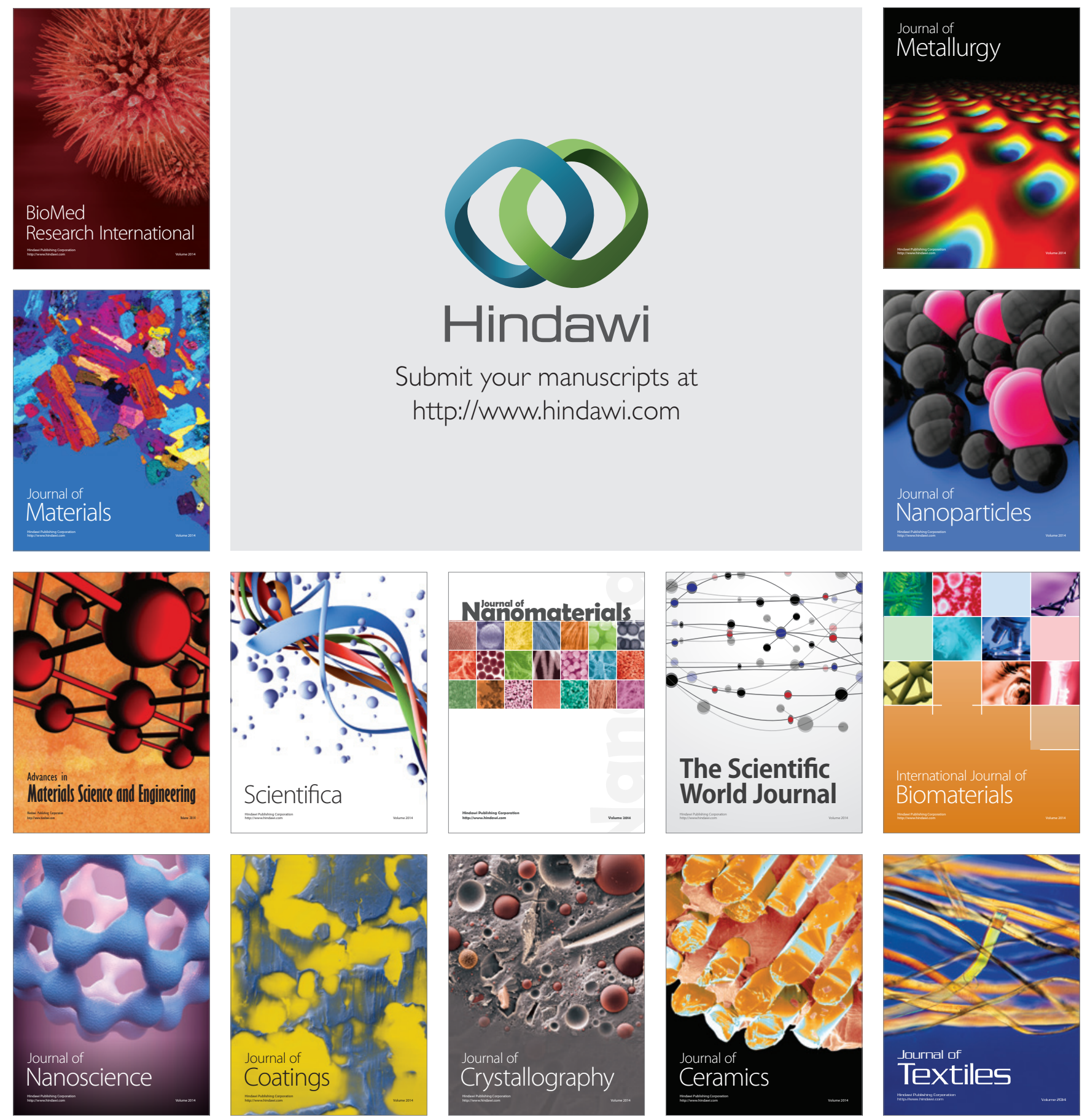